\title{
Review
}

\section{The Genetic and Environmental Factors of Primary Membranous Nephropathy: An Overview from China}

\author{
Xiao-dan Zhang ${ }^{\text {a }}$ Zhao Cui $^{\text {a }}$ Ming-hui Zhao ${ }^{\text {a,b }}$ \\ ${ }^{a}$ Renal Division, Department of Medicine, Peking University First Hospital, Institute of Nephrology, Peking \\ University, Key Laboratory of Renal Disease, Ministry of Health of China, Key Laboratory of CKD Prevention and

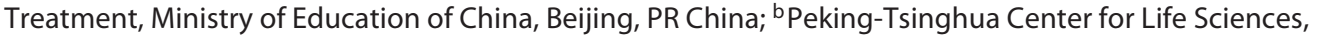 \\ Beijing, PR China
}

\section{Keywords}

Autoimmune response - Disease susceptibility .

Environment pollution - Genetic studies - Membranous nephropathy

\section{Abstract}

Background: Primary membranous nephropathy (pMN) is the most common cause of nephrotic syndrome in adults. The discovery of the 2 autoantigens, M-type phospholipase $A 2$ receptor (PLA2R) and thrombospondin type-1 domaincontaining 7A (THSD7A), has defined $\mathrm{pMN}$ as an autoimmune disease. A remarkable increase in the frequency of pMN in primary glomerular disease was witnessed in China. The genetic and environmental contributors to disease susceptibility have been investigated in these patients. Summary: We reviewed recent publications in genetic and environmental studies of pMN, focusing mainly on those undertaken in China. Following a genome-wide association study, the genegene interaction between the 2 most significant risk factors, PLA2R1 and DQA1, was validated in Chinese patients with MN. Fine mapping on human leukocyte antigen (HLA) locus found that DRB1*1501 and DRB1*0301 were risk alleles. Three amino acid residues on positions 13 and 71 of HLA-
$\mathrm{DR} \beta 1$ chain may confer the susceptibility to $\mathrm{pMN}$ by presenting T-cell epitopes on PLA2R. Another study found that DRB3*0202 was the most likely culprit allele for the signal at $\mathrm{DRB} 1 * 0301$. One environmental risk factor for $\mathrm{pMN}$ has been identified as the long-term exposure to high levels of $\mathrm{PM}_{2.5}$ in Chinese patients with MN. Each $10 \mu \mathrm{g} / \mathrm{m}^{3}$ increase in $\mathrm{PM}_{2.5}$ concentration was associated with $14 \%$ higher odds for $\mathrm{pMN}$ in the regions with $\mathrm{PM}_{2.5}$ above $70 \mu \mathrm{g} / \mathrm{m}^{3}$. Key Message: A gene-environment interaction is suspected as an underlying mechanism for the increasing trend of pMN in China.

(c) 2018 S. Karger AG, Basel

\section{Introduction}

Primary membranous nephropathy (pMN) is the most common cause of nephrotic syndrome in adults $[1,2]$. The histopathology is characterized by the presence of subepithelial immune complexes, diffuse thickening of glomerular basement membrane, and granular staining of IgG and complement C3 along the periphery of glo-

\section{CSN/ERA EDTA Joint Session.}


merular capillary loops [3]. In the landmark study in 2009 by Beck et al. [4] it was shown that $70 \%$ of pMN cases present autoimmune responses against the M-type transmembrane phospholipase A2 receptor (PLA2R), which can be detected on glomerular podocytes and in subepithelial immune deposits. A less common autoantigen is thrombospondin type- 1 domain-containing $7 \mathrm{~A}$ (THSD7A) [5], establishing pMN as a family of autoimmune disorders. Autoantigens or exogenous antigens in the rare situation of neonatal MN include neutral endopeptidase and bovine serum albumin [6,7].

The annual incidence of $\mathrm{pMN}$ has been estimated as 1.2 per 100,000 adults in the United States and in European countries $[8,9]$. It has been reported that the frequency of pMN in primary glomerular disease has been decreasing over the past 3 decades [9-13], with the frequencies in the UK and the United States decreasing from $37 \%$ and $38 \%$ in the 1970 s to $26 \%$ and $15 \%$ in the 2000 s, respectively $[9,10]$. In China, there are little data from epidemiological studies all over the country. One recent study [14] retrospectively analyzed 6,049 renal biopsy patients from a diagnostic referral center and found that the proportion of pMN in primary glomerular disease increased from $17 \%$ in the period of $2003-2007$ to $29 \%$ in the period of 2008-2012 in all age groups. This increase is mainly due to the increase in early stages of $\mathrm{pMN}$ in young patients (14-44 years of age). A similar increasing trend of pMN was observed in many centers from different geographic regions of China $[15,16]$. A nationwide survey [17] has been conducted based on a commercial kidney biopsy database including 71,151 patients from 938 hospitals in 282 cities across China, encompassing all age groups and both tertiary and community hospitals. The frequency of MN doubled from 2004 (12.2\%) to 2014 (24.9\%), whereas the proportions of other major glomerulopathies remained stable. In average, the odds of MN increased by $13 \%$ annually. In China, the tertiary hospitals account for $6.5 \%$ of all hospitals but receive $37 \%$ of all inpatients. Tertiary hospitals in China are mandatorily and automatically submitting electronically the first page of medical records to a Hospital Quality Monitoring System data center. Among all hospitalized patients with primary glomerular disease, an increasing trend of pMN was revealed from $4.5 \%$ in 2010 to $8.8 \%$ in 2015 [unpubl. data]. All these findings demonstrated an increasing trend of pMN in China. One possible reason may be due to the increased awareness, better diagnosis, and improved access to health care in China; however, the mechanism underlying the increase in $\mathrm{MN}$ is worth further investigations.
As an autoimmune disease, both genetic susceptibility and environmental factors are essential for the mechanism of pMN. Couser and Johnson [18] observed the following points in their review. (1) Hereditable risk factors predispose certain individuals to responding to environmental factors in ways that can lead to a nephritogenic autoimmune response (first hit). (2) Exposure to etiologic agents in the environment occurs (second hit), which may be modified by epigenetic factors, and activates the innate immune system through interactions with toll-like receptors and complement. (3) Conversion of a non-antigen-specific innate immune response to an antigen-specific adaptive immune response directed at specific autoantigens can occur through several pathways that may operate simultaneously and in concert. (4) The adaptive immune response generates antigen-specific $\mathrm{T}$ and $\mathrm{B}$ cells, usually directed at antigens that are fixed or "planted" in the glomeruli. These immune reactants, usually through inflammatory effector cells and/or complement, mediate tissue damage.

\section{The Autoimmune Disorders of pMN}

In 1959, Heymann et al. [19] set up a rat model of MN by injection of suspension containing low-speed supernatant of blood-free rat kidney. The deposited immune complex forms in situ rather than in circulation $[20,21]$. Then, the antigen was identified as a glycoprotein of podocyte and brush border membrane, magalin/gp330 [22-24].

In humans, 2 proteins, dipeptidyl-peptidase IV and enkephalinase, expressed on human podocytes, are involved in the immune deposits of MN [25]. In 2004, Debiec et al. [26] reported a fetus patient who prenatally developed severe MN. The mother was deficient in neutral endopeptidase and was immunized against the antigen at the time of or after an earlier miscarriage; the anti-neutral endopeptidase antibodies crossed the placenta and bound to fetal glomerular podocytes. Thus, neutral endopeptidase was defined as the first podocyte antigen responsible for human MN [6, 26]. In 2009, Beck et al. [4] identified PLA2R as the major antigen of human pMN, which is located on normal podocytes and in immune deposits in patients with pMN $[4,27]$. Then, Tomas et al. [5] found that circulating autoantibodies to THSD7A occurred in $5-10 \%$ of PLA2R-negative patients. The structures of these 2 antigens are similar. They both are transmembrane glycoproteins containing large extracellular domains and short cytoplasmic tails [28]. The epitopes on 
PLA2R targeted by anti-PLA2R antibodies were dominantly in the N-terminus, CysR-FnII-CTLD1 region [29]. Two peptides within a 31 -amino acid sequence in the CysR domain were identified as producing $85 \%$ of the inhibition of autoantibody binding to PLA2R [30]. A subsequent study found that the CysR domain appears to be the primary dominant epitope with evidence of epitope spreading toward CTLD1 and CTLD7 domains [31].

Assays for circulating PLA2R antibodies rapidly changed the clinical practice in pMN. Circulating PLA2R antibodies seem to be specific for pMN [32-34]; however, they can also occur in secondary $\mathrm{MN}$, especially the hepatitis B virus-related $\mathrm{MN}$ common in China [35]. The prevalence of positive antibodies varies between different diagnostic centers, from the highest prevalence of $82 \%$ [36] to the lower prevalences of 68\% [37], 59\% [38], and $69 \%$ [39], respectively, in China. The different results may be due to different approaches to antibody detection, including immunofluorescence, ELISA, or Western blot analysis. The antibody titer is associated with disease activity and predicts prognosis and response to treatment $[27,36,38,40-42]$, the disease course after treatment [36, 43], and recurrences after kidney transplantation [44]. A decrease in antibody titers during treatment often precedes proteinuria response [45] and can thus help to differentiate patients who respond to treatment from those who are refractory to treatment.

The finding of PLA2R on podocytes on renal biopsy can also aid in the diagnosis of pMN. Antibodies against another antigen, THSD7A, are of lower prevalence in pMN [5], while they are more frequently detectable in patients with PLA2R-negative $\mathrm{pMN}$, with a prevalence of 7.5\% [39] and 16.4\% [37] in Chinese pMN patients without serum antibodies against PLA2R. Four cases processing dual positive antibodies to PLA2R and THSD7A have been reported; 2 of them are from China [37]. In particular, patients who are negative for PLA2R or THSD7A autoantibodies exhibit a high probability of spontaneous remission but should be screened for malignancy [46].

\section{Genetic Studies of pMN}

\section{Family-Based Studies}

$\mathrm{MN}$ is not a typical hereditary disease in Mendelian terms, apart from rare cases in which more than 1 family member is affected, which indicates a genetic contribution to the disease. In 1984, the Manchester royal infirmary reported 3 sets of brothers (containing a pair of twins) with renal biopsy-proven MN [47]. Elshihabi et al.
[48] summarized 9 families in which MN occurred in siblings, and several other pairs were reported [49-56]. Human leukocyte antigen (HLA) typing confirmed the association between certain HLA types and pMN [47, 53, 56]. In addition to $\mathrm{B} 8, \mathrm{~B} 18, \mathrm{DQ} 2, \mathrm{DQW} 1$, and DQW2, DR3 was detected as the prime marker of susceptibility to $\mathrm{MN}$ [57]. The brothers having DR3 antigens [47] and the pair of father and son having DR3 antigens [56] strongly suggested the role of HLA in pMN.

\section{Genome-Wide Association Studies}

There is only 1 genome-wide association study (GWAS) on pMN [58], which included 3 independent European cohorts from French, Dutch, and British populations. This study examined 242,824 common single nucleotide polymorphisms (SNPs) of 556 patients with pMN as well as 2,338 controls and identified 2 significant genomic loci associated with pMN: chromosome 2q24 contains the gene encoding PLA2R1 (SNP rs4664308), and chromosome $6 \mathrm{p} 21$ contains the gene encoding HLA complex class II HLA-DQ $\alpha 1$ chain (HLA-DQA1) (SNP rs2187668). Then, the study evaluated the effect of the 2 risk alleles on pMN. The odds ratio for being homozygous for the risk allele in DQA1 was 5 times higher than that for being homozygous for the risk allele in PLA2R1. The odds ratio for having this disease was as high as 78.5 for persons who were homozygous for the risk alleles at both HLA-DQA1 and PLA2R1.

Validation studies were conducted worldwide including China. They corroborated a highly significant association between pMN and the risk alleles of HLA-DQA1 and PLA2R1 [59-61]. Furthermore, in a Chinese cohort, $\mathrm{Lv}$ et al. [60] noted gene-gene interactions between the 2 risk alleles and discovered an association between carrying risk alleles and the presence of anti-PLA2R antibodies in serum as well as the expression of PLA2R in glomeruli. The odds ratios of risk genotypes were 1.5 in HLA-DQA1 and 3.4 in PLA2R1. The combination of risk genotypes of 2 genes (rs4664308/rs2187668: AA/GA+AA) conferred an 11.1-fold higher risk for the development of pMN compared with either protective genotype (GG/GG) at both loci. Anti-PLA2R antibodies could be detected in $74 \%$ of patients with the PLA2R1 high-risk genotype and $4 \%$ of patients with the PLA2R1 low-risk genotype. Autoantibodies were detectable in $73 \%$ of patients with both PLA2R1 and HLA-DQA1 high-risk genotypes and in none of the patients with both low-risk genotypes. This study with more than 2,000 participants represents the largest genetic study on pMN and made the new discovery of an association between risk alleles and anti-PLA2R 
antibodies. A study of a Spanish cohort found that the 2 risk alleles could predict response to treatment and disease progression. The carriers of the $\mathrm{pMN}$-susceptible genotypes (A/A and A/G for HLA-DQA1 or A/A for PLA2R1) showed a trend to respond to immunosuppressive therapies [59]. These studies provide functional clues for further investigations of these genes in the pathogenic contribution to $\mathrm{pMN}$.

PLA2R is the major autoantigen of pMN. The results from the GWAS suggest that rare genetic variants within the coding region of PLA2R1 may contribute to antibody formation. Two studies from an Eastern population firstly revealed the association between PLA2R SNPs and $\mathrm{MN}$, but the results differed $[62,63]$. Kim et al. [62] in Korea examined 2 SNPs (rs35771982 and rs3828323) in PLA2R and found that subjects with the C/C genotype of rs35771982 (His300Asp) had a higher susceptibility to pMN. Liu et al. [63] in Taiwan investigated 2 SNPs (rs6757188 and rs35771982) in PLA2R1 and found that the $G$ allele and the $G / G$ genotype of rs35771982 were more common in pMN. A follow-up study sequenced all 30 exons of PLA2R1 from 95 white patients with biopsyproven $\mathrm{pMN}$ to identify rare genetic variants. But no evidence was provided that rare variants within the coding region cause the proposed association between $\mathrm{pMN}$ and the PLA2R1 gene [64]. Gupta et al. [65] reviewed the genetics of MN and proposed that the genetics of PLA2R1 may control the possible enzyme fragmentation pattern of PLA2R1 by a change in amino acid, either by creating or destroying an enzyme cut site, by a change in splice sites, controlling the protein species available for fragmentation, or by a change in the level of transcript, leading to higher levels of peptides. The genetics of DQA1 will shape the amino acid structure of its receptor groove, thus defining and restricting the possible peptide sequences available from PLA2R1 that will fit the groove.

At variance with European and East Asian populations, no association was found in African Americans [66]. In a large analysis in Northern American, PLA2R1 variants were only associated with PLA2R-related $M N$ in Caucasians but not associated with MN in African Americans with either PLA2R-positive or -negative MN. Similarly, HLA-DQA1 SNP rs2187668 was positively associated with PLA2R-positive MN and negatively associated with PLA2R-negative MN in Caucasians, while it was associated with PLA2R-positive but not with PLA2R-negative $\mathrm{MN}$ in African Americans [66]. Larsen et al. [67] found that APOL1 was a risk allele in African American patients. They included 120 PLA2R-related MN patients and screened the presence of $A P O L 1$ risk alleles. There were 46 cases with 0,51 cases with 1 , and 23 cases with 2 APOL1 risk alleles. Besides, patients with 2 APOL1 risk alleles suffered from severer pathological damage, which suggests that the presence of APOL1 risk alleles might serve as an acceleration factor in this disease.

\section{Association Studies Focused on HLA Loci}

In the GWAS on pMN, variants within the HLA region conferred the greatest risk of disease. Polymorphism within the HLA is associated with almost every autoimmune disease studied to date, but the identity of causal variation in many diseases has been hampered by the strong linkage disequilibrium across disease-associated haplotypes. The HLA region resides on chromosome 6 p21.3 and is among the most gene-dense portions of DNA, with gene products ranging from antigen-binding molecules and receptors to signaling factors. The region can be subdivided into class I, II, and III. Class I encompasses HLA-A, $-\mathrm{B}$, and $-\mathrm{C}$ that function as presenters of peptides to cytotoxic T cells; class II consists of HLA-DR and HLA-DQ molecules that present epitopes to $\mathrm{CD} 4^{+} \mathrm{T}$ cells; and class III includes genes of several components in the complement system, such as C4, factor B and C2 $[68,69]$.

The first report [70] of genetic contributions of the HLA locus to the risk of pMN was published in the UK, in 1979, with the finding of HLA-DR3. This result was confirmed by a series of studies [71, 72]. In the European Caucasoid cohort, DRB $1 * 0301$ has the strongest association with British pMN, while the Greek pMN association with DRB ${ }^{*} 0301$ is weaker [73]. The top SNP in GWAS on pMN, rs2187668, in the gene HLA-DQA1, is a wellestablished tag SNP for DRB1*0301 in Northern European populations [74]. The haplotype $\mathrm{B}^{*} 0801$ DRB1*0301-DQA $1 * 0501-D Q B 1 * 0201$ is highly conserved in Northern European populations and is associated with several autoimmune diseases, including pMN $[75,76]$. Besides, TAP1 (lying within the MHC II region) was also associated with pMN [77]. The association between pMN and DRB1*1501 was discovered in a Japanese cohort, together with DR2 and DQ1 [78, 79]. They reported a risk haplotype DRB1*1501-DQB1*0602 in $\mathrm{pMN}$ [80].

Two studies from China provide novel insights into the role of specific HLA alleles in pMN [81]. Cui et al. [82] performed 4-digit resolution typing of HLA-DRB1, DQA1, DQB1, and DPB1 genes, followed by a case-control association analysis in 261 patients and 599 healthy controls, and pointed to 2 classical alleles, DRB1*1501 and DRB1*0301, with highly significant independent ef- 
fects on the risk of pMN among Han Chinese. The DRB1*1501 and DRB $1 * 0301$ alleles had large, independent, and genome-wide significant effects with allelic odds ratios of 4.65 and 3.96, respectively. These alleles were also significantly associated with circulating antiPLA2R antibodies. Similar to SNPs in GWAS, both HLA alleles exhibited statistical interaction with the PLA2R1 variant rs4664308. Notably, the homozygosity for risk alleles at the PLA2R1 locus combined with DRB1*1501 or $\mathrm{DRB} 1 * 0301$ positivity conferred an up to 30 -fold increased risk of pMN. This synergistic effect is suggestive of a physical interaction between DR $\beta 1$ molecules and the PLA2R epitope(s) during the process of antigen presentation. The analysis of individual amino acid substitutions within HLA proteins further narrowed down the search to the amino acid positions 13 and 71 within the HLADR $\beta 1$ chain. Both of these positions participate in the formation of the fourth peptide-binding pocket of the HLADR $\beta 1$ chain. Furthermore, in silico modeling of PLA2R peptides presented by the susceptible HLA molecule revealed several candidate epitopes that require experimental validation. Interestingly, modeling sequence variants of PLA2R1 had little effect on T-cell epitope prediction, suggesting that coding variants in PLA2R1 are less likely to alter the immunogenicity of its gene product.

The second study by Le et al. [83] performed a comprehensive analysis by targeted high-throughput sequencing of all HLA genes in the region, including class I and class II genes, in 99 anti-PLA2R-positive pMN cases and 100 healthy controls. This study confirmed the association of DRB1*1501 with anti-PLA2R-positive pMN and suggested DRB3*0202 as the second independent risk factor, subsequently replicating both of these associations in an independent cohort of 293 cases and 285 controls. The effects were significantly larger, with allelic odds ratios of 24.9 and 17.7, respectively. These larger effects are likely explained by differences in the ascertainment of cases: the first study included all cases of pMN, but the second study used PLA2R-related pMN. Notably, DRB3 alleles were not typed in the first study, but DRB3*0202 resides on the same haplotype as DRB1*0301, thus the results of both studies are technically in full agreement. In fact, the second study suggests that DRB3*0202 is the most likely culprit allele explaining the reported signal at DRB $1 * 0301$, considering its stronger statistical significance and the conditional analysis that removes any residual signal at DRB $1 * 0301$ after accounting for both DRB1*1501 and DRB3*0202. Secondary genotype-phenotype correlation analyses revealed that DRB1*1501 was strongly associated with an earlier age at

Genetic and Environmental Factors of pMN in China disease onset. Among PLA2R-positive pMN cases, patients carrying DRB1* 1501 presented at a median age of 35 years compared to a median age of 50 years for all other patients.

\section{Environmental Studies of pMN}

In the genetically susceptible individuals (first hit), the exposure to some environmental factors (second hit) is suspected to trigger the disease. China comprises $20 \%$ of the world population. With rapid developments in its economy and urbanization, especially during the past decade, air pollution has become a public health problem in some cities. From 2004 to 2014 [84], 3-year average levels of AOD-derived $\mathrm{PM}_{2.5}$, the particulate matter of $<2.5 \mu \mathrm{m}$, have been increasing up to a plateau in 2008. In 2008, levels of $\mathrm{PM}_{2.5}$ exposure varied from 8.1 to $110.5 \mu \mathrm{g} / \mathrm{m}^{3}$ with a mean of $55.6 \mu \mathrm{g} / \mathrm{m}^{3}$. This level was much higher than that in many developed countries, such as the United States (mean, $12 \mu \mathrm{g} / \mathrm{m}^{3}$ ), the UK (mean, $14 \mu \mathrm{g} / \mathrm{m}^{3}$ ), and Japan (mean, $10 \mu \mathrm{g} / \mathrm{m}^{3}$ ), and was comparable to developing countries, such as India (mean, $59 \mu \mathrm{g} / \mathrm{m}^{3}$ ) [85].

Exposure to air pollution, especially $\mathrm{PM}_{2.5}$, has been associated with increased death and incidence of cardiovascular events [86]. Animal studies have shown that exposure to fine particulate promotes the production of autoantibodies and immune complexes and results in immune dysregulation, which is implicated in the pathogenesis of some glomerulopathies [87, 88]. It has been hypothesized that cytokines generated in the airways in response to air pollution can spill over into the circulation, influencing autoimmune responses and distant events [89]. Air pollution increases the circulating levels of inflammation mediators, such as TNF- $\alpha$, IL-6, and plasminogen activator inhibitor-1 $[88,90]$, and genetic polymorphisms in these cytokines are associated with the development of MN [91-95].

An increasing trend of pMN has been observed in many developing countries, such as Pakistan [96], Czech Republic [97], and India [98, 99]. The frequency of pMN in India increased almost by 2-fold during 1999-2008 $[98,99]$. In an Indian cohort with high-concentration exposure to $\mathrm{PM}_{2.5}$, during the period of 1971-2002, there was a steady increase in pMN prevalence [100]. On the contrary, in developed countries like France, the increasing trend of pMN happened in the 1990s and has been reversed since 1996 [101, 102], which could also be observed in Brazil [103] and the United States [104]. pMN was shown to be declining in other East Asian countries 
with lower $\mathrm{PM}_{2.5}$ exposure levels, such as Japan [105] and Korea $[106,107]$, where the pMN prevalence was stable during the past 10 years.

Yang et al. [108] conducted a correlation study in Taipei and reported that the exposure to $\mathrm{PM}_{10}$, but not $\mathrm{PM}_{2.5}$, during the previous year was associated with renal function reduction. A recent study from Mainland China correlated the rising incidence of $\mathrm{pMN}$ with the deterioration of air pollution. Xu et al. [17] observed a remarkable rising trend in the frequency of pMN from $12.2 \%$ in 2004 to $24.9 \%$ in 2014 . The frequency of pMN was higher in the Northern region of China, especially in Hebei province, the most polluted area in China. Most importantly, they found that long-term exposure to high levels of $\mathrm{PM}_{2.5}$ was associated with an increased risk of pMN after controlling for confounders, including age, gender, geographic region, level of hospital for biopsy, pathologic laboratory, clinical syndrome, and year of biopsy. The relationship appeared to be nonlinear: each $10 \mu \mathrm{g} / \mathrm{m}^{3}$ increase in $\mathrm{PM}_{2.5}$ concentration was associated with $14 \%$ higher odds for $\mathrm{pMN}$ in the regions with a $\mathrm{PM}_{2.5}$ concentration above $70 \mu \mathrm{g} / \mathrm{m}^{3}$. The curve was flat at $\mathrm{PM}_{2.5}$ below $70 \mu \mathrm{g} / \mathrm{m}^{3}$. The annual increase in odds for $\mathrm{pMN}$ was greater in the cities with a higher $\mathrm{PM}_{2.5}$ slope even after adjusting for geographic region. Assuming a causal relationship, $15.2 \%$ of pMN in China could be attributable to $\mathrm{PM}_{2.5}$ air pollution exposure. Another analysis [unpubl. data] using the national inpatient registration database of tertiary hospitals in China confirmed the increasing percentage of pMN among all primary glomerular nephropathy, doubling from $4.6 \%$ in 2010 to $8.8 \%$ in 2015 . In North and Northeast China, it had exceeded the frequency of IgA nephropathy since 2014. The patients clustered in Hebei province and Guangxi province. The association between exposure to $\mathrm{PM}_{2.5}$ and increases in $\mathrm{pMN}$ was confirmed in Northern China demarcated by Yangtze River. However, in the South of China, a close association was observed between the frequency of pMN and the Zhuang population, the largest minority population of China, but not $\mathrm{PM}_{2.5}$.

In addition to air pollution, some other environmental factors, such as bacterial infections and occupational exposure, also participate in the development of pMN. There are several studies on the association between $\mathrm{He}$ licobacter pylori infection and MN. The infection rate of $H$. pylori was found to be significantly higher (66\%) in MN patients than in age-matched healthy controls (44\%) $[109,110]$. A case report described a patient with $\mathrm{MN}$ whose nephrotic-range proteinuria was markedly reduced after the eradication of gastric $H$. pylori infection
[111]. A Chinese study did not find any difference in the $H$. pylori infection rate between $\mathrm{MN}$ patients and healthy controls but did find an immune reaction between kidney cells and anti-H. pylori antibody [112]. Occupational exposure is considered as another external factor in the development of MN. A case-control study was designed to investigate the role of occupational hydrocarbon exposure, which included 36 biopsy-proven $\mathrm{pMN}$ patients and 36 healthy controls and collected their lifetime hydrocarbon exposure assessed by a validated questionnaire. The study found that the exposure to hydrocarbons was significantly greater in pMN patients than in controls, which suggests a relationship between lifetime hydrocarbon exposure and the development of $\mathrm{MN}$ [113].

\section{Future Perspectives on Genetic and Environmental Studies of pMN}

Many discoveries on genetic and environmental risk factors of pMN have provided clues for pathogenesis research. Follow-up studies on HLA analysis will require a large-scale comprehensive sequencing effort involving the entire locus, also including noncoding segments that may regulate HLA gene expression. Such studies would be ideally performed in cohorts of diverse ancestries, including representative cohorts of Asian, European, and African ancestry. The mechanism underlying the association between long-term exposure to high levels of $\mathrm{PM}_{2.5}$ and the increasing risk of $\mathrm{pMN}$ is unknown. It is postulated that $\mathrm{PM}_{2.5}$ might bind transcript factors in podocytes and increase PLA2R antigen expression and consequently initiate antibody production. However, whether these links are causal or simply associated with the disease needs further investigation. Furthermore, like the genegene interaction that has been proven to contribute to pMN development, the environmental factors may enhance the genetic propensity for pMN in the polluted areas. To confirm this hypothesis, further explorations of gene-environment interactions are needed to calculate the proportion of patients with risk genetic as well as environmental elements, and the odds ratio for $\mathrm{pMN}$ with a combination of risk alleles and high-level pollution regions. A better understanding of the mechanisms and correlations between altered immune responses to environmental pathogens and initiation of the autoimmune processes could help guide the discovery of new biomarkers and stimulate more effective approaches to both prevention and therapy of the disease. 


\section{Acknowledgement}

This work was supported by grants of the Natural Science Foundation of China to the Innovation Research Group (81621092), the Outstanding Young Scholar (81622009), and other programs (81330020), and the Capital of Clinical Characteristics and Applied Research Fund (Z161100000516039).

\section{Conflict of Interest Statement}

None of the authors have any competing interests.

\section{References}

1 Ronco P, Debiec H: Pathophysiological advances in membranous nephropathy: time for a shift in patient's care. Lancet 2015;385: 1983-1992.

-2 Deegens JK, Wetzels JF: Membranous nephropathy in the older adult: epidemiology, diagnosis and management. Drugs Aging 2007;24:717-732.

3 Fogo AB, Lusco MA, Najafian B, et al: AJKD atlas of renal pathology: membranous nephropathy. Nephrol Dial Transplant 2011;26: 3425-3426.

4 Beck LH Jr, Bonegio RG, Lambeau G, et al: M-type phospholipase A2 receptor as target antigen in idiopathic membranous nephropathy. N Engl J Med 2009;361:11-21.

5 Tomas NM, Beck LH Jr, Meyer-Schwesinger $\mathrm{C}$, et al: Thrombospondin type-1 domaincontaining 7A in idiopathic membranous nephropathy. N Engl J Med 2014;371:22772287.

6 Debiec H, Guigonis V, Mougenot B, et al: Antenatal membranous glomerulonephritis due to anti-neutral endopeptidase antibodies. N Engl J Med 2002;346:2053-2060.

7 Debiec H, Lefeu F, Kemper MJ, et al: Earlychildhood membranous nephropathy due to cationic bovine serum albumin. N Engl J Med 2011;364:2101-2110.

-8 Floege J, Amann K: Primary glomerulonephritides. Lancet 2016;387:2036-2048.

-9 Hanko JB, Mullan RN, O’Rourke DM, et al The changing pattern of adult primary glomerular disease. Nephrol Dial Transplant 2009;24:3050-3054.

10 Braden GL, Mulhern JG, O'Shea MH, et al: Changing incidence of glomerular diseases in adults. Am J Kidney Dis 2000;35:878-883.

11 Stratta P, Segoloni GP, Canavese C, et al: Incidence of biopsy-proven primary glomerulonephritis in an Italian province. Am J Kidney Dis 1996;27:631-639.

- 12 Woo KT, Chan CM, Chin YM, et al: Global evolutionary trend of the prevalence of primary glomerulonephritis over the past three decades. Nephron Clin Pract 2010;116:c337c346.

13 Golay V, Trivedi M, Abraham A, et al: The spectrum of glomerular diseases in a single center: a clinicopathological correlation. Indian J Nephrol 2013;23:168-175.

Genetic and Environmental Factors of pMN in China
14 Zhu P, Zhou FD, Wang SX, et al: Increasing frequency of idiopathic membranous nephropathy in primary glomerular disease: a 10 -year renal biopsy study from a single Chinese nephrology center. Nephrology (Carlton) 2015;20:560-566.

15 Tang LJ, Yao J, Kong XL, et al: Increasing prevalence of membranous nephropathy in patients with primary glomerular diseases: a cross-sectional study in China. Nephrology 2017;22:168-173.

16 Pan XX, Xu J, Ren H, et al: Changing spectrum of biopsy-proven primary glomerular diseases over the past 15 years: a single-center study in China. Contrib Nephrol 2013;181: 22-30.

$17 \mathrm{Xu}$ X, Wang G, Chen N, et al: Long-term exposure to air pollution and increased risk of membranous nephropathy in china. J Am Soc Nephrol 2016;27:3739-3746.

18 Couser WG, Johnson RJ: The etiology of glomerulonephritis: roles of infection and autoimmunity. Kidney Int 2014;86:905-914.

19 Heymann W, Hackel DB, Harwood S, et al: Production of nephrotic syndrome in rats by Freund's adjuvants and rat kidney suspensions. Proc Soc Exp Biol Med 1959;100:660664.

20 Van Damme BJ, Fleuren GJ, Bakker WW, et al: Experimental glomerulonephritis in the rat induced by antibodies directed against tubular antigens. V. Fixed glomerular antigens in the pathogenesis of heterologous immune complex glomerulonephritis. Lab Invest 1978:38:502-510.

21 Couser WG, Salant DJ: In situ immune complex formation and glomerular injury. Kidney Int 1980;17:1-13.

22 Kerjaschki D, Farquhar MG: The pathogenic antigen of Heymann nephritis is a membrane glycoprotein of the renal proximal tubule brush border. Proc Natl Acad Sci USA 1982; 79:5557-5561.

23 Kerjaschki D, Farquhar MG: Immunocytochemical localization of the Heymann nephritis antigen (GP330) in glomerular epithelial cells of normal Lewis rats. J Exp Med 1983; 157:667-686.

24 Saito A, Pietromonaco S, Loo AK, et al: Complete cloning and sequencing of rat gp330/"megalin", a distinctive member of the low density lipoprotein receptor gene family. Proc Natl Acad Sci USA 1994;91:9725-9729.
25 Ronco P, Allegri L, Brianti E, et al: Antigenic targets in epimembranous glomerulonephritis: experimental data and potential application in human pathology. Appl Pathol 1989;7: 85-98.

26 Debiec H, Nauta J, Coulet F, et al: Role of truncating mutations in MME gene in fetomaternal alloimmunisation and antenatal glomerulopathies. Lancet 2004;364:12521259.

27 Hoxha E, Thiele I, Zahner G, et al: Phospholipase A2 receptor autoantibodies and clinical outcome in patients with primary membranous nephropathy. J Am Soc Nephrol 2014; 25:1357-1366

28 Beck LH Jr: PLA2R and THSD7A: Disparate paths to the same disease? J Am Soc Nephrol 2017;28:2579-2589.

29 Kao L, Lam V, Waldman M, et al: Identification of the immunodominant epitope region in phospholipase $\mathrm{A} 2$ receptor-mediating autoantibody binding in idiopathic membranous nephropathy. J Am Soc Nephrol 2015; 26:291-301.

30 Fresquet M, Jowitt TA, Gummadova J, et al: Identification of a major epitope recognized by PLA2R autoantibodies in primary membranous nephropathy. J Am Soc Nephrol 2015;26:302-313.

31 Seitz-Polski B, Dolla G, Payre C, et al: Epitope spreading of autoantibody response to PLA2R associates with poor prognosis in membranous nephropathy. J Am Soc Nephrol 2015; 27:1517-1533.

$32 \mathrm{Du} \mathrm{Y,} \mathrm{Li} \mathrm{J,} \mathrm{He} \mathrm{F,} \mathrm{et} \mathrm{al:} \mathrm{The} \mathrm{diagnosis} \mathrm{accuracy}$ of PLA2R-AB in the diagnosis of idiopathic membranous nephropathy: a meta-analysis. PLoS One 2014;9:e104936.

33 Hu SL, Wang D, Gou WJ, et al: Diagnostic value of phospholipase A2 receptor in idiopathic membranous nephropathy: a systematic review and meta-analysis. J Nephrol 2014; 27:111-116.

34 Dai HZ, Zhang HH, He YN: Diagnostic accuracy of PLA2R autoantibodies and glomerular staining for the differentiation of idiopathic and secondary membranous nephropathy: an updated meta-analysis. Sci Rep 2015; 5:8803

35 Xie Q, Li Y, Xue J, et al: Renal phospholipase A2 receptor in hepatitis $B$ virus-associated membranous nephropathy. Am J Nephrol 2015;41:345-353. 
-36 Qin WS, Beck LH Jr, Zeng C, et al: Anti-phospholipase A2 receptor antibody in membranous nephropathy. J Am Soc Nephrol 2011; 22:1137-1143.

-37 Wang J, Cui Z, Lu J, et al: Circulating antibodies against thrombospondin type-I domaincontaining 7A in Chinese patients with idiopathic membranous nephropathy. Clin J Am Soc Nephrol 2017;12:1642-1651.

38 Pang L, Zhang AM, Li HX, et al: Serum antiPLA2R antibody and glomerular PLA2R deposition in Chinese patients with membranous nephropathy. Medicine (Baltimore) 2017;96:e7218.

-39 Lin L, Wang WM, Pan XX, et al: Biomarkers to detect membranous nephropathy in Chinese patients. Oncotarget 2016;7:6786867879.

-40 Kanigicherla D, Gummadova J, McKenzie EA, et al: Anti-PLA2R antibodies measured by ELISA predict long-term outcome in a prevalent population of patients with idiopathic membranous nephropathy. Kidney Int 2013;83:940-948.

-41 Ruggenenti P, Debiec H, Ruggiero B, et al: Anti-phospholipase A2 receptor antibody titer predicts post-rituximab outcome of membranous nephropathy. J Am Soc Nephrol 2015;26:2545-2558.

42 Hofstra JM, Beck LH Jr, Beck DM, et al: Antiphospholipase A receptor antibodies correlate with clinical status in idiopathic membranous nephropathy. Clin J Am Soc Nephrol 2011;6:1286-1291.

-43 Bech AP, Hofstra JM, Brenchley PE, et al: Association of anti-PLA(2)R antibodies with outcomes after immunosuppressive therapy in idiopathic membranous nephropathy. Clin J Am Soc Nephrol 2014;9:1386-1392.

-44 Kattah A, Ayalon R, Beck LH Jr, et al: Antiphospholipase A (2) receptor antibodies in recurrent membranous nephropathy. Am J Transplant 2015;15:1349-1359.

45 Beck LH Jr, Fervenza FC, Beck DM, et al: Rituximab-induced depletion of anti-PLA2R autoantibodies predicts response in membranous nephropathy. J Am Soc Nephrol 2011; 22:1543-1550.

-46 Hoxha E, Harendza S, Pinnschmidt HO, et al: Spontaneous remission of proteinuria is a frequent event in phospholipase A2 receptor antibody negative patients with membranous nephropathy. Nephrol Dial Transplant 2015; 30:1862-1869.

-47 Short CD, Feehally J, Gokal R, et al: Familial membranous nephropathy. Br Med J (Clin Res Ed) 1984;289:1500.

48 Elshihabi I, Kaye CI, Brzowski A: Membranous nephropathy in two human leukocyte antigen-identical brothers. J Pediatr 1993; 123:940-942.

49 Sato K, Oguchi H, Hora K, et al: Idiopathic membranous nephropathy in two brothers. Nephron 1987;46:174-178.

50 Vangelista A, Tazzari R, Bonomini V: Idiopathic membranous nephropathy in 2 twin brothers. Nephron 1988;50:79-80.
51 Vivarelli M, Emma F, Pellé T, et al: Genetic homogeneity but IgG subclass-dependent clinical variability of alloimmune membranous nephropathy with anti-neutral endopeptidase antibodies. Kidney Int 2015;87: 602-609.

52 Meroni M, Volpi A, Usberti M, et al: Two brothers with idiopathic membranous nephropathy and familial sensorineural deafness. Am J Kidney Dis 1990;15:269-272.

53 Mezzano S, Rojas G, Ardiles L, et al: Idiopathic membranous nephropathy, associated with HLA-DRw3 and not related to monocytephagocyte system $\mathrm{Fc}$ receptor dysfunction, in father and son. Nephron 1991;58:320-324.

54 Grcevska L, Polenakovic M: Idiopathic membranous nephropathy (IMN) in two HLAidentical brothers with different outcome of the disease. Clin Nephrol 1999;52:194-196.

55 Izzi C, Sanna-Cherchi S, Prati E, et al: Familial aggregation of primary glomerulonephritis in an Italian population isolate: Valtrompia study. Kidney Int 2006;69:1033-1040.

-56 Guella A, Akhtar M, Ronco P: Idiopathic membranous nephropathy in identical twins. Am J Kidney Dis 1997;29:115-118.

57 Dyer PA, Short CD, Clarke EA, et al: HLA antigen and gene polymorphisms and haplotypes established by family studies in membranous nephropathy. Nephrol Dial Transplant Suppl 1992;1:42-47.

58 Stanescu HC, Arcos-Burgos M, Medlar A, et al: Risk HLA-DQA1 and PLA(2)R1 alleles in idiopathic membranous nephropathy. N Engl J Med 2011;364:616-626.

59 Bullich G, Ballarín J, Oliver A, et al: HLADQA1 and PLA2R1 polymorphisms and risk of idiopathic membranous nephropathy. Clin J Am Soc Nephrol 2014;9:335-343.

60 Lv JC, Hou WY, Zhou XJ, et al: Interaction between PLA2R1 and HLA-DQA1 variants associates with anti-PLA2R antibodies and membranous nephropathy. J Am Soc Nephrol 2013;24:1323-1329.

61 Ramachandran R, Kumar V, Kumar A, et al: PLA2R antibodies, glomerular PLA2R deposits and variations in PLA2R1 and HLA-DQA1 genes in primary membranous nephropathy in South Asians. Nephrol Dial Transplant 2016;31:1486-1493.

62 Kim S, Chin HJ, Na KY, et al: Single nucleotide polymorphisms in the phospholipase A2 receptor gene are associated with genetic susceptibility to idiopathic membranous nephropathy. Nephron Clin Pract 2011; 117:c253-c258.

63 Liu YH, Chen CH, Chen SY, et al: Association of phospholipase A2 receptor 1 polymorphisms with idiopathic membranous nephropathy in Chinese patients in Taiwan. J Biomed Sci 2010;17:81.

64 Coenen MJ, Hofstra JM, Debiec H, et al: Phospholipase A2 receptor (PLA2R1) sequence variants in idiopathic membranous nephropathy. J Am Soc Nephrol 2013;24:677-683.
65 Gupta S, Köttgen A, Hoxha E, et al: Genetics of membranous nephropathy. Nephrol Dial Transplant 2017, DOI: 10.1093/ndt/gfx296.

66 Saeed M, Beggs ML, Walker PD, et al: PLA2Rassociated membranous glomerulopathy is modulated by common variants in PLA2R1 and HLA-DQA1 genes. Genes Immun 2014; 15:556-561.

67 Larsen CP, Beggs ML, Walker PD, et al: Histopathologic effect of APOL1 risk alleles in PLA2R-associated membranous glomerulopathy. Am J Kidney Dis 2014;64:161-163.

68 Meyer D, C Aguiar VR, Bitarello BD, et al: A genomic perspective on HLA evolution. Immunogenetics 2018;70:5-27.

69 Gruen JR, Weissman SM: Evolving views of the major histocompatibility complex. Blood 1997;90:4252-4265.

-70 Klouda P T, Manos J, Acheson E J, et al: Strong association between idiopathic membranous nephropathy and HLA-DRw3. Lancet 1979;2:770-771.

-71 Müller GA, Müller C, Liebau G, et al: Strong association of idiopathic membranous nephropathy (IMN) with HLA DR3 and MT2 without involvement of HLA-B18 and no association to BfF1. Tissue Antigens 1981;17: 332-337.

72 Le Petit JC, Laurent B, Berthoux FC: HLADR3 and idiopathic membranous nephritis (IMN) association. Tissue Antigens 1982;20: 227-228.

73 Vaughan RW, Tighe MR, Boki K, et al: An analysis of HLA class II gene polymorphism in British and Greek idiopathic membranous nephropathy patients. Eur J Immunogenet 1995;22:179-186.

74 Fernando MM, Stevens CR, Sabeti PC, et al Identification of two independent risk factors for lupus within the MHC in United Kingdom families. PLoS Genet 2007;3:e192.

-75 Fernando MM, Stevens CR, Walsh EC, et al Defining the role of the MHC in autoimmunity: a review and pooled analysis. PLoS Genet 2008;4:e1000024.

76 Vaughan RW, Demaine G, Welsh KI: A DQAl allele is strongly associated with idiopathic membranous nephropathy. Tissue Antigens 1989;34:261-269.

77 Chevrier D, Giral M, Perrichot R, et al: Idiopathic and secondary membranous nephropathy and polymorphism at TAPl and HLADMA loci. Tissue Antigens 1997;50:164-169.

78 Hiki Y, Kobayashi Y, Itoh I, et al: Strong association of HLA-DR2 and MTI with idiopathic membranous nephropathy in Japan. Kidney Int 1984;25:953-957.

79 Ogahara S, Naito S, Abe K, et al: Analysis of HLA class II genes in Japanese patients with idiopathic membranous glomerulonephritis. Kidney Int 1992;41:175-182.

80 Thiri M, Honda K, Kashiwase K, et al: Highdensity association mapping and interaction analysis of PLA2R1 and HLA regions with idiopathic membranous nephropathy in Japanese. Sci Rep 2016;6:38189. 
81 Mladkova N, Kiryluk K: Genetic complexities of the HLA region and idiopathic membranous nephropathy. J Am Soc Nephrol 2017; 28:1331-1334.

-82 Cui Z, Xie LJ, Chen FJ, et al: MHC class II risk alleles and amino acid residues in idiopathic membranous nephropathy. J Am Soc Nephrol 2017;28:1651-1664.

83 Le WB, Shi JS, Zhang T, et al: HLA-DRB1 1501 and HLA-DRB3 0202 in PLA2R-related membranous nephropathy. J Am Soc Nephrol 2017;28:1642-1650.

84 van Donkelaar A, Martin RV, Brauer M, et al: Use of satellite observations for long-term exposure assessment of global concentrations of fine particulate matter. Environ Health Perspect $2015 ; 123: 135-143$.

85 World Health Organization: Ambient (Outdoor) Air Pollution Database, 2014. http:// www.who.int/topics/air_pollution/en/ (accessed May 15, 2014).

86 Miller KA, Siscovick DS, Sheppard L, et al: Long-term exposure to air pollution and incidence of cardiovascular events in women. $\mathrm{N}$ Engl J Med 2007;356:447-458.

87 Pfau JC, Brown JM, Holian A: Silica-exposed mice generate autoantibodies to apoptotic cells. Toxicology 2004;195:167-176.

-88 Brown JM, Pfau JC, Holian A: Immunoglobulin and lymphocyte responses following silica exposure in New Zealand mixed mice. Inhal Toxicol 2004; 16:133-139.

89 Ritz SA: Air pollution as a potential contributor to the "epidemic" of autoimmune disease. Med Hypotheses 2010;74:110-117.

90 Panasevich S, Leander K, Rosenlund M, et al: Associations of long- and short-term air pollution exposure with markers of inflammation and coagulation in a population sample. Occup Environ Med 2009;66:747-753.

91 Thibaudin D, Thibaudin L, Berthoux P, et al: TNFA2 and $\mathrm{d} 2$ alleles of the tumor necrosis factor alpha gene polymorphism are associated with onset/occurrence of idiopathic membranous nephropathy. Kidney Int 2007; 71:431-437.

92 Bantis C, Heering PJ, Aker S, et al: Tumor necrosis factor-alpha gene G-308A polymorphism is a risk factor for the development of membranous glomerulonephritis. Am J Nephrol 2006;26:12-15.
93 Chen CH, Shu KH, Wen MC, et al: Impact of plasminogen activator inhibitor-1 gene polymorphisms on primary membranous nephropathy. Nephrol Dial Transplant 2008;23:3166-3173.

94 Luo Y, Wang C, Tu H: Impact of the 4G/5G polymorphism in the plasminogen activator inhibitor-1 gene on primary nephrotic syndrome. Mol Med Rep 2014;9:894-898.

95 Chen SY, Chen CH, Huang YC, et al: Effect of IL-6 C-572G polymorphism on idiopathic membranous nephropathy risk in a Han Chinese population. Ren Fail 2010;32:11721176.

96 Kazi JI, Mubarak M, Ahmed E, et al: Spectrum of glomerulonephritides in adults with nephrotic syndrome in Pakistan. Clin Exp Nephrol 2009;13:38-43.

97 Rychlík I, Jancová E, Tesař V, et al: The Czech registry of renal biopsies. Occurrence of renal diseases in the years 1994-2000. Nephrol Dial Transplant 2004; 19:30403049.

98 Das U, Dakshinamurty KV, Prayaga A: Pattern of biopsy-proven renal disease in a single center of south India: 19 years experience. Indian J Nephrol 2011;21:250-257.

99 Beniwal P, Pursnani L, Sharma S, et al: A clinicopathologic study of glomerular disease: a single-center, five-year retrospective study from Northwest India. Saudi J Kidney Dis Transpl 2016;27:997-1005.

100 Narasimhan B, Chacko B, John GT, et al: Characterization of kidney lesions in Indian adults: towards a renal biopsy registry. J Nephrol 2006;19:205-210.

101 Simon P, Ramee MP, Boulahrouz R, et al: Epidemiologic data of primary glomerular diseases in western France. Kidney Int 2004; 66:905-908.

102 Simon P, Ramée MP, Autuly V, et al: Epidemiology of primary glomerular diseases in a French region. Variations according to period and age. Kidney Int 1994;46:11921198.

103 Polito MG, de Moura LA, Kirsztajn GM: An overview on frequency of renal biopsy diagnosis in Brazil: clinical and pathological patterns based on 9,617 native kidney biopsies. Nephrol Dial Transplant 2010;25: 490-496.
04 Swaminathan S, Leung N, Lager DJ, et al: Changing incidence of glomerular disease in Olmsted County, Minnesota: a 30-year renal biopsy study. Clin J Am Soc Nephrol 2006; 1: 483-487.

105 Sugiyama H, Yokoyama H, Sato H, et al: Japan Renal Biopsy Registry: the first nationwide, web-based, and prospective registry system of renal biopsies in Japan. Clin Exp Nephrol 2011;15:493-503.

106 Chang JH, Kim DK, Kim HW, et al: Changing prevalence of glomerular diseases in Korean adults: a review of 20 years of experience. Nephrol Dial Transplant 2009;24: 2406-2410.

107 Choi IJ, Jeong HJ, Han DS, et al: An analysis of 4,514 cases of renal biopsy in Korea. Yonsei Med J 2001;42:247-254.

108 Yang YR, Chen YM, Chen SY, et al: Associations between long-term particulate matter exposure and adult renal function in the Taipei metropolis. Environ Health Perspect 2017; 125:602-607.

109 Moriyama T, Kaneko T, Fujii M, et al: High prevalence of Helicobacter pylori infection in Japanese patients with membranous nephropathy. Aliment Pharmacol Ther 2007; 24:189-193.

110 Kronbichler A, Kerschbaum J, Mayer G: The influence and role of microbial factors in autoimmune kidney diseases: a systematic review. J Immunol Res 2015;2015:858027.

111 Li Q, Lin X, Wu Z, et al: Immuno-histochemistry analysis of Helicobacter pylori antigen in renal biopsy specimens from patients with glomerulonephritis. Saudi J Kidney Dis Transpl 2013;24:751-758.

112 Sugimoto T, Furukawa T, Maeda T, et al: Marked reduction of proteinuria after eradication of gastric Helicobacter pylori infection in a patient with membranous nephropathy: coincidental or associated? Intern Med 2007;46:1483-1484.

113 Gradden CW, Pai P, Hindell P, et al: Membranous nephropathy, hydrocarbon exposure and genetic variants of hydrocarbon detoxification. QJM 2001;94:79-87. 